\title{
Investigating isotopic functional indices to reveal changes in the structure and functioning of benthic communities
}

\author{
Rigolet Carinne 1, 2, Thiebaut Eric ${ }^{2,3}$, Brind'Amour Anik ${ }^{4}$, Dubois Stanislas 1, *
}

1 IFREMER, DYNECO, Lab Ecol Benth, F-29280 Plouzane, France.

2 Univ Paris 04, Univ Paris 06, UMR 7144, Stn Biol Roscoff, F-29688 Roscoff, France.

${ }^{3}$ CNRS, UMR 7144, Adaptat \& Divers Milieu Marin, F-29680 Roscoff, France.

4 IFREMER, DRBE, Lab Ecol \& Modeles Halieut, F-44311 Nantes 03, France.

*Corresponding author : Stanislas Dubois, email address : stanislas.dubois@ifremer.fr

\begin{abstract}
:
1. With the use of stable isotopes, new concepts have emerged based on the idea that the ecological niche can be approximated by the isotopic niche defined as a $\delta$-space area with isotopic $\delta$ values as coordinates. This study aims to (i) redefine functional indices originally based on quantitative biological traits of species and demonstrate the ecological significance of newly defined isotopic functional indices (IFI) in a $\delta$-isotopic space, (ii) compare IFI using biomass data with existing unweighted isotopic indices using only isotopic compositions.
\end{abstract}

2. Using a community-wide approach, we tested IFI using isotopic compositions of a large set of associated species from two marine benthic communities widely reported in coastal shallow waters: the common Amphiura filiformis muddy-sand community and the engineered Haploops nirae sandy-mud community. Biomass and isotopic composition $(13 \mathrm{C}$ and $15 \mathrm{~N})$ of all species were measured during four seasons.

3. IFI were calculated in the isotopic space defined by the two communities, and variations were analysed: (i) isotopic functional richness indices measure the overall extent of the community trophic niche. They are higher in the Haploops community due to a higher diversity in food sources but also to longer food chains. (ii) isotopic functional evenness indices quantify the regularity in species distribution and the density in species packing. They showed that the biomass is concentrated at the edges of the food web in the Haploops community, outside the isotopic range of the main food source. (iii) isotopic functional divergence indices quantify the degree to which species distribution maximizes the divergence. They showed a larger utilization of secondary food sources in the Haploops community.

4. The IFI variations responded according to expectations overall, based on the extensive knowledge of those communities. Results highlighted that IFI weighted with species biomass provide new insights into how the structure of energy accumulation as biomass between species is likely to underpin community structure and the interplay between structural components of richness, diversity and evenness of biomass distribution. 
Keywords : community-wide metrics, functional diversity, habitats, stable isotopes, trophic niche width 


\section{Introduction}

In the context of increasing efforts to understand the relationship between the diversity and functioning of ecosystems (Hooper et al. 2005; Cardinale et al. 2012), relevant approaches to assess ecosystem functioning have emerged and developed. The functional diversity that measures the distribution and range of what organisms do in communities and ecosystems (i.e. species functions) has been widely recognized as a principal driver of ecosystem processes (Petchey, Hector \& Gaston 2004) and a good estimator of the health and/or vulnerability of an ecosystem (Tilman et al. 1997; Hulot et al. 2000; Tillin et al. 2006). While species richness was first assumed to be an implicit measure of functional diversity, it does not explicitly incorporate the biological traits governing ecological processes. The most relevant approach to quantifying functional diversity is the analysis of species biological traits (Lavorel \& Garnier 2002), which has led to the proposal of diverse measures of functional diversity over the last decade (see reviews by Mouchet et al. 2010; Schleuter et al. 2010; Mouillot et al. 2011). Among others, Mason et al. (2005) and Villéger, Mason \& Mouillot (2008) suggested that functional diversity can be broken down into three major components: (1) functional richness, which measures the amount of functional space occupied by a community in $t$-traits dimensional space; (2) functional evenness, which measures the regularity of the species distribution in functional trait space; and (3) functional divergence, which measures the degree to which species distribution maximizes the divergence.

The quantification of energy flows between or within ecosystem components is another approach to quantifying ecosystem functions (Cardinale et al. 2012). Here, stable isotopes have become a common and often powerful tool to investigate trophic pathways in ecosystems, animal foraging behaviours and inter- and intra-specific trophic competition (Boecklen et al. 2011). Beyond the traditional use of stable isotopes to reconstruct diets, new ideas have emerged regarding determination of Hutchinson's ecological niche concept using stable isotopes. Newsome et al. (2007) noticed that stable isotopic compositions reflect information relating to use of the physical habitat (e.g. size, hydro-climatic conditions) and its trophic features (e.g. diversity, foraging strategy): two crucial factors defining the ecological niche of an organism. The isotopic niche can therefore be a way to illustrate the realized trophic niche (Bearhop et al. 2004, Dubois \& Colombo 2014). Additionally, Layman et al. (2007) suggested using simple metrics based on stable isotopic compositions that would quantitatively characterize the "morphospace" defined in an isotopic space at a communitywide scale. These straightforward metrics cover different aspects of trophic structure including the trophic diversity and trophic redundancy. In these applications, all species are considered equal in the isotopic space. However, biomass or abundance is unequally distributed among species such that those with the largest biomass are likely to have the largest impact on ecosystem functioning, especially via the food web (Grime 1998). Existing isotopic metrics developed in Layman et al. (2007) or Jackson et al. (2011) may give similar results when two communities are actually structurally and functionally different. Omitting the species biomass distribution from the calculation of such indices ultimately leads to a disregard of energy distribution and flow, as well as the relative forces in inter-species trophic interactions.

In this study, we suggest using biological trait-based indices, commonly used to assess functional diversity (FD) indices, to depict and quantify structural and ultimately functional characteristics of complex food webs. These recently developed FD indices gather the biological traits of organisms into an $n$-dimensional trait-space to define functional niches. They incorporate information about how abundance or biomass (a parameter directly linked to the amount of energy a species assimilates) is distributed among species traits (Mouillot et al. 2013). We estimated FD indices with species isotopic signatures rather than with traditional biological traits, thereby shifting from a multi-dimensional trait-space to an isotopic $\delta$-space. 
We tested isotopic FD indices on marine benthic ecosystems, using the Amphiura filiformis (Müller 1776) benthic community commonly occurring on the NW European continental shelf. In coastal bays of South Brittany, this community is partly colonized by the gregarious tubiculous amphipod engineer species Haploops nirae (Kaim-Malka 1976), which has been spreading over muddy benthic habitats in recent decades (Rigolet et al. 2012).

Ecosystem engineers can substantially change environmental conditions and resource availability via non-trophic interactions, thus affecting other species and altering community attributes of natural species assemblages (Jones, Lawton \& Shachak 1997; Badano \& Cavieres 2006). Dense tube mats formed by Haploops nirae significantly modify sediment features, controlling diversity and abundances of associated species, and creating a complex set of positive and negative interactions (Rigolet, Dubois \& Thiébaut 2014a). Changes in biodiversity caused by an engineer species may disrupt the ecological functions performed by natural species assemblages, and modify energy transfer in the ecosystem. First observations using stable isotopes suggest that Haploops affects food-web functioning by promoting primary production of the microphytobenthos, and modifying the diversity of food sources for benthic consumers, hence minimizing interspecific food competition among suspensionfeeders (Rigolet, Thiébaut \& Dubois 2014b).

In this study, we developed new community-wide isotopic indices to emphasize different attributes of functional diversity and to combine stable isotopic compositions with species biomass. Using natural changes driven by colonization by the engineer amphipod Haploops nirae of the surrounding uncolonized Amphiura filiformis community, we investigated the ability of these metrics to react and predict changes in food-web functioning. We discuss the advances that these isotopic indices offer for food-web research.

\section{Material and Methods}

\section{SAMPLING PROTOCOL}

Macrobenthic samples were collected in the Bay of Concarneau, Bay of Biscay (France), an area characterized by soft-bottom substrata, spanning from muddy to muddy-sands, with a depth ranging from 15 to $35 \mathrm{~m}$ (see geographical details in Rigolet et al. 2014b). The west of the bay is composed of muddy-sands and sandy-muds inhabited by a benthic community dominated by the echinoderm Amphiura filiformis (hereafter referred to as the Amphiura community). The centre of the bay is composed of pure muds supporting a dense population of the tubiculous amphipod Haploops nirae (hereafter the Haploops community), forming a habitat with a dense tube mat (ca. 10000 tubes.m-2) and a unique species assemblage (Rigolet et al. 2014a).

Using a preliminary map of the seabed, we selected six stations to compare the food web structure of the Haploops community with the adjacent uncolonized Amphiura community (3 stations in each community). The six stations were sampled during each season (winter, spring, summer and autumn).To assess the biomass of the benthic macrofauna (retained on a 1-mm mesh) within each community, a $0.1 \mathrm{~m}^{2}$ Van Veen grab was used for sampling (3 replicates per station, total of 18 replicates). Macrofauna was identified to the lowest taxonomic level (i.e. generally the species level) and counted. Biomass of each taxon was measured by weight loss after combustion at $450^{\circ} \mathrm{C}$ for 6 hours (ash-free dry weight). Since organisms were preserved in formalin, a correction factor of 1.2 was applied, as suggested by Brey (1986), to compensate the weight loss caused by the preservative.

Quantitative estimates of over-dispersed megafauna species densities were made with a modified benthic beam-trawl (width $=2$ meters, sampled area $=c a .2300 \mathrm{~m}^{2}$ ). Megafaunal organisms were sorted and identified on board, counted and weighed (wet weight). Specific weight-to-weight conversion factors were used to compare megafauna wet weight and macrofauna ash-free dry weight (Ricciardi \& Bourget 1998); all biomasses were then 
converted to wet weight. All biomass and abundance data was expressed per $\mathrm{m} 2$ to ensure comparability.

\section{ISOTOPIC ANALYSES}

To investigate the trophic structure within each community, additional grab and trawl samples were performed to collect the largest possible diversity of macrofaunal and megafaunal organisms for isotopic analyses at all stations for the four seasons (see supplementary material 1 for species list). All species collected were immediately sorted and kept frozen $\left(-20^{\circ} \mathrm{C}\right)$. Isotopic species compositions from winter and summer have been published elsewhere (Rigolet et al. 2014b). At least three individuals were analysed for each species in each community and season. For very small species, several individuals were pooled to reach the minimum dry weight for stable isotope analyses. Isotopic analyses were performed on muscle tissue samples for megafauna or large macrofauna organisms, but the whole body was used for small macrofauna species (i.e. crustaceans and polychaetes). In this case, special care was taken to remove all gut contents by dissection. Samples were rinsed with Milli-Q water and freeze-dried. Samples of species containing calcium carbonate (i.e. crustaceans and echinoderms) were split and a subsample was acidified $(10 \% \mathrm{HCl})$ to remove any inorganic carbonates. Nitrogen signatures were obtained from untreated subsamples. Because lipid content was low in tissue samples (low $\mathrm{C}: \mathrm{N}$ ratio: 3-5), isotopic compositions were not corrected. The isotopic carbon $\left(\delta^{13} \mathrm{C}\right)$ and nitrogen $\left(\delta^{15} \mathrm{~N}\right)$ compositions were then measured with a stable isotope ratio mass spectrometer Finnigan MAT Delta Plus, operating in continuous-flow mode, coupled to an elemental analyser Carlo Erba NC2500 (Cornell University, Stable Isotope Laboratory, New York). Isotopic ratios for carbon and nitrogen were expressed using standard $\delta$ notation (Sulzman 2007). Analytical precision was $0.2 \%$ (calculated from internal standards). Species analysed for stable isotopes represent between 79 and $93 \%$ of the benthic standing stock biomass. We therefore considered that the essential part of the benthic community was analysed for stable isotopes, providing a very good overview of the food web in the communities investigated.

\section{DESCRIPTION OF FUNCTIONAL INDICES AND DATA ANALYSES}

We used seven functional diversity (FD) indices available in the literature. These were designed to incorporate information about species abundances or biomass and emphasize different attributes of functional diversity (i.e. functional richness, divergence and evenness) (Mason et al. 2005). We applied these "weighted" multidimensional functional diversity indices to isotopic data in a two-dimensional isotopic $\delta$-space by considering the isotopic compositions of species $\left(\delta^{13} \mathrm{C}\right.$ and $\left.\delta^{15} \mathrm{~N}\right)$ from a community rather than their biological traits. The information contained within consumer stable isotope compositions provides quantitative information on both resource (bionomic) and habitat (scenopoetic) use. We decided to weight the relative importance of each species in the food web using biomass rather than number of individuals, since biomass is directly related to metabolism and secondary production and is thus a more relevant proxy for the functional impact of an individual species within an ecosystem (Grime 1998). These seven "weighted" indices were compared with four "unweighted" indices, already developed in a $\delta$ space (Layman et al. 2007; Jackson et al. 2011).

The resulting 11 isotopic functional indices (IFI) are fully described and graphically illustrated in supplementary material 2. They are grouped according to the 3 facets of functional diversity (richness, divergence and evenness) and interpreted from an isotopic (i.e. trophic) point of view:

(1) Isotopic Functional Richness (IFR) provides a quantitative indication of the extent of the isotopic niche space of the entire community. Indices used to quantify IFR give indications of 
whether the available trophic space is used or not by the species composing the community. Overall, low IFR indicates that some of the resources potentially available to the community are unused. Low IFR also possibly indicates a reduced productivity in the community (Petchey 2003), or a decreased buffering capacity against environmental (e.g. food sources) fluctuations (Mason et al. 2005). Three indices were used as estimators of the IFR (i.e. IFRic, SEAc and Hullbiom). Only one (i.e. Hullbiom) is weighted by species biomass. Additionally, following Mouillot et al. (2013), we calculated the Isotopic Functional shift value (IFshift) as the non-overlap percentage between the convex hulls of the target communities. This can be used as a quantitative measure of trophic niche similarity among communities, but is not an index per se and was hence not reported.

(2) The Isotopic Functional Divergence (IFD) provides information on how the isotopic functional space is filled by species. It measures the degree to which species distribution in an isotopic space maximises the trophic divergence within the community. Overall, IFD indices are weighted by biomasses. High values of IFD indicate that biomass-dominant species occupy the isotopic space more densely at its edges, revealing a trophic specialisation and thus a high degree of niche differentiation in the community. In such cases, communities may have increased ecosystem functions. Conversely, low IFD values indicate that biomasses are dominated by more generalist species (i.e. species closer to the centre of gravity) and that fewer functions or ecological processes are achieved by the community. Five indices were calculated as estimators of the IFD (CD, IFDiv, IFDis, IFSpe and IFEnt). One index (CD) does not account for species' biomasses in its calculation.

(3) Isotopic Functional Evenness (IFE) provides information on how the isotopic space is filled by species. Unlike IFD, IFE indicates how evenly spaced species are in the occupied isotopic space (i.e. with equal distances between species but also with equal biomasses). IFE may therefore be seen as the degree to which the biomass of a community is distributed in the niche space to allow effective utilisation of the entire range of resource available (Mason et al. 2005). A low IFE suggests that the community is composed of clusters of species (i.e. packed species) and implies trophic redundancy and competition for food. It also suggests that resources (whilst potentially available) are potentially not used by the community. In contrast, a high IFE indicates an even distribution of species and biomasses in the $\delta$-space, resulting in higher functional regularity and allowing optimal resource use through species complementarity. Ultimately, high IFE could result in higher productivity, stability and resilience in communities (Hooper et al. 2005). Three indices were used as estimators of IFE (NND, IFEve and IFOri). One (NND) does not account for the species biomass. Biomass data are usually time-consuming to obtain. Yet, in almost all natural communities, most of the biomass of the food webs consists of just a few species (Cohen \& Luczak 1992). We therefore developed a dual approach to compute IFI: either we calculated IFI by considering all species sampled (considered as $100 \%$ of the biomass) or we selected only species that accounted for the greatest part of the benthic biomass (i.e. $75 \%$ of the relative benthic biomass). In this later case, we reduced the number of species to exclude very small and/or rare species, so that only species presumably playing a significant functional role were considered. Indices weighted by biomasses should not be largely affected by whether $100 \%$ or $75 \%$ of the community biomass is considered. Because the remaining $25 \%$ of the biomass corresponds to either less abundant or outlying species, we expected unweighted indices to be most affected.

A principal component analysis (PCA) was performed to provide an overview of the relationships between the calculated indices and to compare the properties of the trophic food webs of the Haploops and Amphiura communities. All computations of IFI and analyses were performed using the $\mathrm{R}$ package ( $\mathrm{R}$ Development Core Team, 2014). Scripts were modified according to available online scripts and libraries (SIAR and FD packages). 


\section{Results}

The -spaces ( $\delta{ }^{13} \mathrm{C} v s \delta{ }^{15} \mathrm{~N}$ biplots) overlapped for all seasons, revealing a strong similarity in isotopic unweighted hulls based on vertex species for the Amphiura and Haploops communities (Figs.1a-h). Calculations of IFshift (a measure of non-overlap) spanned from 36 to $40 \%$ and showed that the two food webs share at least $60 \%$ of the overall isotopic space in winter, spring and summer. In autumn, IFshift increased to 53\%, revealing more differences in isotopic niche between the two food webs. The inclusion of the biomass data on regular isotopic bi-plots visually highlighted major trophic pathways, providing two different pictures for each of the food webs (Figs. 1ip). Five to seven species accounted for 67.1 to $83.0 \%$ of the total biomass in the Amphiura community (Figs.1i-1). The brittle star Amphiura filiformis, the large bivalve Dosinia lupines as well as the holothurian Thyone fusus and the polychaete Maldane glebifex constituted the major part of the benthic biomass in this community in all seasons. As for the Haploops community, only two species (the tubiculous amphipod H. nirae and the large bivalve Polititapes virgineus) consistently accounted for the bulk of the benthic biomass (between 43.0 and $71.0 \%$ of the total biomass)(Figs. 1m-p). The sipunculid Aspidosiphon muelleri represented a significant proportion of the biomass in all seasons except spring. Finally, the predator polychaete Glycera fallax accounted for a large part of the biomass in the Haploops community in spring and autumn. When only species accounting for $75 \%$ of the total biomass were considered, the two food webs shared less similarity, with a higher IFshift (Figs.1e-h).

When IFI were calculated on the complete food webs (i.e. all species isotopically analysed), Amphiura and Haploops communities differed for all indices, for all 3 components of functional diversity and in all seasons (Fig. 2). Overall, IFR indices (i.e. IFRic, SEAc and Hullbiom) followed the same trend and revealed that the extent of the trophic niche of the entire community is higher in the Haploops food web, with the exception of winter. It suggests that individuals in the Amphiura community occupy a smaller isotopic functional space. In winter, IFRic and SEAc followed the same trend (i.e. lower values in the Haploops community) while the Hullbiom, which is weighted by the biomass of species, showed the opposite trend. However, when considering $75 \%$ of the benthic biomass, the sign of the difference between the two communities remained the same. Differences were more pronounced for the unweighted indices (IFRic and SEAc).

When IFD indices were calculated on all species, all of the four indices weighted by species biomasses (i.e. IFDiv, IFDis, IFSpe, IFEnt) showed the same trend in all seasons, with values being consistently higher in the Haploops food web. Higher values of IFD reported in the Haploops community suggested that species that accounted for the largest part of the biomass in the Haploops community exhibited isotopic signatures more distant from the centre of gravity of the food web than in the Amphiura community. Inversely, the unweighted index (CD) was systematically lower in the Haploops community, although differences were small between the two communities. When only dominant species were considered, the sign of the difference between the two communities remained the same, again with the exception of CD. The magnitude of the differences between the two communities did not change except for the unweighted $\mathrm{CD}$ index in winter and autumn, where differences are more pronounced. Also, the magnitude of increase in CD for $75 \%$ biomass $v s 100 \%$ biomass for autumn and winter is no greater than the decreases seen in $75 \%$ biomass vs $100 \%$ biomass for some of the biomassweighted IFI measures (e.g. IFDiv summer, IFEnt spring). Calculations of IFE indices on the overall food web showed that the two indices weighted by species biomasses (i.e. IFEve and IFOri) consistently followed the same trend although they showed no consistent pattern through the year (Fig. 2). While the Haploops community showed higher values in winter and summer, indicating that biomasses are more regularly distributed in the Haploops community, contrasting results are observed in spring and autumn. The equivalent unweighted index 
(NND) showed consistently lower values in the Haploops community except in summer where the differences are close to zero. Computation of IFE indices on only dominant species showed erratic changes for IFEve and IFOri, while no change was observed for NND.

The Principal Component Analysis illustrated the overall behaviour of all indices as well as an overview of the differences between Haploops and Amphiura food webs (Fig.3). The first two PCA components explained $51.83 \%$ and $29.25 \%$ of the total variance, respectively, while the third axis explained only $9.8 \%$ of the variance. The first axis discriminated the two communities relatively well and was mainly explained by the biomass weighted IFD indices (IFDiv, IFDis, IFSpeand IFEnt), but interestingly also by Hullbiom, the only biomassweighted IFR index. Biomass-weighted IFD indices are thus mainly involved in the discrimination between the two communities. While CD, NND, IFEve and IFOri largely explained the variance from the second axis, they were of less importance in the discrimination of the two communities.

\section{Discussion}

Trophic diversity is typically described with indices that focus on 3 independent components of functional diversity (functional Richness, Divergence and Evenness) originally calculated from morphological and biological traits (Villéger, Mason \& Mouillot 2008; Laliberté \& Legendre, 2010; Clark et al. 2012; Mouillot et al. 2013). In this study, these indices were calculated using isotopic signatures of species, transferring a multidimensional trait space into a bidimensional $\delta$-space. The use of a $\delta^{13} \mathrm{C}-\delta^{15} \mathrm{~N}$ isotopic biplot as a unique 2-dimensionnal space inherently combines several biological traits related to the trophic niche of each species, such as foraging behaviour and feeding movements, morphological characteristics of feeding apparatus and inter-species relationships including food competition and prey-predator pathways. The isotopic space can then be seen as a multidimensional ecological space containing what ecologists refer to as the trophic niche (Newsome et al. 2007). In comparison with previous indices already proposed to characterize the food-web structure (see review by Layman et al. 2012), one original aspect of this approach is that the relative biomass of each species is considered in most indices.

Ecosystem engineer species make a good example for applying these indices, as they significantly modify their habitat and are recognized to influence ecosystem structure and function worldwide (Reise 2002). The two adjacent communities studied are physically well separated, yet sufficiently close to access the same planktonic primary production from the open ocean. This allows comparison using stable isotopes, as their trophic baseline is the same. Both communities are also well documented. The colonization of the engineer amphipod Haploops nirae over the surrounding Amphiura filiformis community significantly increases species diversity and abundances but also completely modifies the associated species assemblage (Rigolet et al, 2014a). The analysis of turnover in benthic assemblages revealed that the Haploops community shared very few species (ca. only 30\%) with surrounding communities (Rigolet et al. 2014a). Stable isotope compositions of Haploops tubes and sediments revealed that the benthic primary production of the microphytobenthos (MPB) is enhanced in the Haploops community (Rigolet et al. 2014b). The additional MPB food source in the Haploops community might be expected to increase the size of the community trophic niche, decrease the competition for food or lead to higher trophic differentiation between species, even if a portion of this food source is exported. Richer diversity in food sources associated with engineered habitats appears to be a general feature in intertidal communities (Passarelli et al. 2012).

Existing isotopic metrics (i.e. SEAc in Jackson et al. 2011 or IFRic, CD and NND in Layman et al. 2007) and biomass-weighted IFI provide a different perspective of food-web structures and trophic pathways. Haploops and Amphiura communities have contrasting food-web 
functioning, as they differ for all of the 3 components of isotopic functional diversity. More precisely, IFD indices (supplemental material 2) mainly differentiate the Haploops community from the Amphiura community, revealing a stronger degree of trophic specialisation and niche differentiation in the former. While all components of functional diversity are important indicators of the functioning of ecological systems, we consider the functional divergence as its strong feature. In the context of species and habitat loss, several authors have suggested that the preservation of ecosystems functions is linked to ecological differences between species (i.e. the niche complementarity concept). For example, in grasslands, plant communities with the highest number of functional groups are more productive (Hector el al, 1999). Likewise, the diversity of prey and consumers has a positive effect on the secondary production of aquatic ecosystems, highlighting that an increase in prey diversity may enhance energy transfer within an ecosystem (Gamfeldt, Hillebrand \& Jonsson 2005). The authors suggested that this was partly due to niche complementarity because ecological differences between species lead to more complete utilization of resources. Higher specialization among species in the Haploops community allows a greater range of functional traits to be represented in the ecosystem, providing opportunities to maximize resource use and thus augment productivity. Estimates of secondary production in Haploops and Amphiura communities (Rigolet et al. 2012 and unpublished data) agree with this conclusion: while the benthic stock biomass is halved in the Haploops community, the two communities show the same values of secondary production.

Greater functional redundancy is thought to lead to a greater resilience to environmental changes, as it allows a community to cope with diversity loss (Raffaelli 2006). The higher trophic redundancy reported in the Amphiura community probably offers greater resistance to disturbances, while the opposite trend in the Haploops community likely decreases its buffering capacity against disturbances.

\section{ISOTOPIC FUNCTIONAL RICHNESS (IFR) INDICES}

Overall, the three indices used to quantify IFR suggested that the Haploops community had a larger trophic niche than the surrounding Amphiura community, as a direct result of the previous findings showing additional food sources (MPB) associated with the Haploops community (Rigolet et al. 2014b). Potential food sources available for micro- and macrograzers create new trophic niche space for organisms and contribute to broadening diet diversity and ultimately the isotopic space, especially on the $\delta^{13} \mathrm{C}$ axis (Layman et al. 2012). The larger trophic niche within the Haploops community also results from a higher diversity of trophic levels, such as a higher density and biomass of macrofauna predators (e.g. polychaete Glycera fallax), shown on the $\delta^{15} \mathrm{~N}$ axis (Fig. 1). This result agrees with previous investigations showing that high densities of amphipods host larger abundances (and biomass) of macrofaunal predators such as polychaetes or large nemerteans (McDermott 1993).

Some dissimilarity emerged between biomass-weighted (Hullbiom) and unweighted equivalent indices (IFRic and SEAc). Opposite trends are observed between weighted and unweighted indices in winter. The pattern of PCA variable correlation also revealed that biomass data offer valuable information otherwise overlooked with unweighted indices (Fig. 3). Indeed, the Hullbiom index indicates that species that broaden the isotopic niche in the Amphiura community are actually not abundant and/or have a small biomass, unlike for the Haploops community. Also as expected, the Hullbiom index was not affected whether one considered 100 or $75 \%$ of the community biomass, but unweighted indices were deeply affected by the removal of less abundant species (or species with low weight in the community). Unweighted IFR indices are therefore very sensitive to outlying species, for example, those with low abundance or small biomass. This is especially true for species occupying a very narrow, specialized trophic niche, such as symbiotic species: their isotopic 
signatures often contribute to broadening the isotopic space while their abundance/biomass in coastal benthic habitat usually remains minor.

\section{ISOTOPIC FUNCTIONAL DIVERGENCE (IFD) INDICES}

Overall, IFD indicates that the biomass is more concentrated towards the edges food web in the Haploops community than in the Amphiura community (Fig. 2). It means that a higher proportion of the biomass in the Haploops community is produced outside the isotopic range of the main food source (i.e. the open-sea phytoplankton, see Rigolet et al. 2014b) and implies a larger utilisation of food sources other than phytoplankton-derived food. In isotopic space, unless the isotopic composition is exactly the same, additional food sources add species isotopic compositions and associated biomass, hence increasing isotopic divergence. Conversely, in the Amphiura community, the suspension-feeders (representing most of the biomass) graze on the same food source (phytoplankton), giving most species a similar isotopic signature, associated with the phytoplankton.

Dissimilarities between unweighted (CD) and biomass-weighted indices (IFDiv, IFDis, IFSpe and IFEnt) also emerged for IFD indices, as revealed by their consistent opposite trend. Results stressed the need to account for species biomasses in food-web studies, as interpretation of the isotopic signatures alone can potentially lead to opposing conclusions regarding inter-species competition for food and maximization of trophic diversity. Variations in IFD indices weighted by species biomass also prove not to be sensitive to the number of species and community comparison can be based on $75 \%$ of the community biomass. The IFSpe index thus appears to provide more biologically relevant information than the CD index.

\section{ISOTOPIC FUNCTIONAL EVENNESS (IFE) INDICES}

Contrary to the results obtained for the two other components of the isotopic functional diversity, indices used to quantify the IFE showed no clear and consistent pattern through the year. In some seasons, the Haploops community showed higher IFE values, revealing a lower density of species packing and thus less inter-species competition for food (Fig. 2). Higher IFE values are a consequence of larger diversity in food sources, reducing the competition for food between species and allowing a larger diversity of mixed diets. Resources are then more evenly distributed among species. More specifically, Rigolet et al. (2014b) showed that competition between the two main co-occurring suspension-feeders Haploops nirae and the clam Polititapes virgineus was very limited, as $P$. virgineus was primarily feeding on resuspended benthic microalgae (MPB) while $H$. nirae was grazing on phytoplankton. This is not the case in the Amphiura community, where the majority of suspension-feeders are clustered in the same isotopic space (Figs.1c, 1g), revealing more dietary overlap between species and thus more competition for the same resource. The opposite trend was detected in IFE indices in spring and autumn. Because weighted IFE indices take into account the regularity of space between species but also the evenness of biomass distribution, it is likely that IFE indices respond randomly for communities with very unbalanced species distributions, such as disturbed communities (e.g. by pollution), communities dominated by an invasive species or those structured by an engineer species. Seasonal variations indicate that IFE indices should be interpreted with caution.

Contrary to expectations, biomass-weighted IFE results differed when considering only the species representing $75 \%$ of the biomass. Because of their mathematical construction, both IFEve and IFOri seemed to be sensitive to the low (and uneven) number of species. This concern was addressed by Brind'Amour \& Dubois (2013) for other communitywide metrics: simulated food-web structures showed that the mean nearest neighbor distance (NND) or its standard deviation (SDNND) are the two most sensitive metrics to the number of species. 
IFEve and IFOri are NND-like metrics and even though they are weighted with species biomass, they remain very sensitive to the number of species, underlining the need for caution when interpreting IFE indices.

\section{RELEVANCE AND ECOLOGICAL APPLICATIONS OF IFI}

One major difference between isotopic trait metrics and other metrics is that there are no unique associations between isotopic composition and biological traits. Ultimately, this means that two co-occurring species with different biological traits can potentially share the same trophic niche, while metrics based on biological measurements would classify them into different functional groups. Another difference is that isotopic compositions give assimilated signals, as a combination of diet composition, trophic level and foraging behaviour, reflecting realized functional niches, from a trophic-oriented point of view. Biological/morphological traits reflect potential functional niches but are broader. Isotopic functional indices appear as complementary tools to existing functional metrics (Mason et al. 2005, Villéger, Mason \& Mouillot 2008).

Incorporating biomass data into $\delta$-spaces drastically affects how one can picture and quantify food-web structure. In many communities, most of the biomass is represented by a small number of species (Cohen \& Luczak 1992). The biomass threshold above which species should be considered still needs to be discussed as this can affect results profoundly. When comparing two different communities or one community before and after a disturbance, we recommend being selective in the biomass threshold and using dominance curves such as " $k$ dominance" (Clarke 1990) to help draw a relevant threshold. Reconstruction of food-web structures using simulated abundance data should also provide relevant information as to how those isotopic functional metrics behave. Considering only $75 \%$ of the biomass appears a good compromise between the laboratory time necessary to obtain data and potential gains to improve existing isotopic indices (Layman et al. 2012). Running unweighted isotopic indices (i.e. TA, CD, NND, SEAc) on a small number of species has been proven to largely underestimate real values of a whole community. Using bootstrap techniques, several authors showed that a minimum of ca. 20 species is necessary to represent the whole community (Jackson et al. 2011, Brind'Amour \& Dubois 2013).

Biomass-weighted IFI might then considerably reduce the number of species needed for a relevant picture of food-web functioning, although further investigation might still be needed to model IFI behaviour according to food-web structure and biomass thresholds. However, once the threshold of the biomass has been established for two communities compared with weighted indices (e.g. 75\% in our example), it is interesting that differences in species number are no longer an issue but a result per se. The differences for both 100\% (all species) and $75 \%$ (less than 10 species) biomass of communities are small (Fig. 2), mostly because the sensitivity of isotopic metrics to the number of species is largely reduced by weighting isotopic compositions with biomass.

Isotopic Diversity Indices are derived from metrics that meet the criteria and properties of sensitivity and independence for community-wide metrics (Mason et al. 2003, Ricotta 2005, Villéger Mason \& Mouillot2008) and are fully operational, providing biomass data are available. Unlike the biological-trait approach, which needs (1) relevant a priori trait selection and (2) an adequate number of measured traits (Petchey \& Gaston 2002), the $\delta^{13} \mathrm{C}-\delta^{15} \mathrm{~N}$ isotopic space integrates all biological traits related to food capture, foraging behavior and inter-species / inter-individual relationships in a single 2D-space. Of course, all isotopic indices can be estimated in $n$-dimension isotopic space. Since $34 \mathrm{~S}$ isotope values are increasing in the literature, once could easily think of deploying IFI in a ${ }^{13} \mathrm{C}-{ }^{15} \mathrm{~N}-{ }^{34} \mathrm{~S} 3 \mathrm{D}$ plot. Hoeinghaus \& Zeug (2008) or Schleuter et al. (2010) warned about potential pitfalls of using isotopic metrics for comparing communities or ecosystems. Potentially, different values can 
be obtained from food webs with similar trophic structure if food source isotopic compositions exhibit different $\delta 13 \mathrm{C}$ and/or $\delta 15 \mathrm{~N}$, also meaning that differences in species isotopic niches do not necessarily equate to differences in functional roles, and vice versa. This pitfall can be avoided by knowing the isotopic terrain and using isotopic metrics wisely. When comparing communities with different food sources or one community before and after any change, we recommend either standardizing isotopic compositions or directly incorporating potential changes in food sources into difference testing with isotopic metrics, to avoid being misled under particular set of circumstances. Practically, the present study avoided this pitfall by using data from two marine benthic communities with similar allochtonous food sources. However, seasonal variations in IFI were not interpreted, as isotopic compositions of trophic baselines (terrestrial inputs, phytoplankton or benthic microalgae) indeed changed according to seasons. To address this issue, Newsome et al. (2007) suggested using all organisms' isotopic signatures transformed into a $p$-space combining the proportions of all potential food sources in each consumer's diet. While this idea offers a broader comparison between systems and/or seasons, output results of mixing models often have too many uncertainties to comfortably calculate IFI in such $p$-space.

In the current study, prior knowledge of rather profound differences in the communities convinced us that the differences in isotopic metrics have some ecological significance. Even so, isotopic metrics do not necessarily require prior information on investigated systems. Because a set of metrics is available on each facet of the functional diversity, one can be confident in detecting changes between two communities if all metrics follow the same trend. Also, in order to test whether differences in isotopic space are significant, we suggest randomizing the dataset to produce mean (and dispersion) values for isotopic metrics (e.g. Brind'Amour \& Dubois 2013).

In conclusion, analyses of isotopic richness, divergence and evenness provide a framework for detecting changes in functional food-web structure between communities or following change. The set of Isotopic Functional Indices provides relevant community-wide metrics from extensive application of stable isotope ratios by ecologists, while offering new perspectives for using $\delta$-spaces by focusing on biomass distribution within the food web. Applications to other cases are needed to better predict the ecological behaviour of such isotopic metrics. Mathematical null models are also necessary to provide statistical tests assessing the significance of ecological differences shown by these isotopic metrics.

\section{Acknowledgments}

C.R. was supported by a Region Bretagne postgraduate award. S.F.D. was funded by the National Program for Coastal Environment (EC2CO) and the Total Foundation. The authors wish to thank J.D. Gaffet, X. Caisey, P. Laffargue and the crew of the RV Thalia for the collection of benthic organisms. Dr F. Nunes and Helen McCombie edited this manuscript. The authors are also grateful to the associate editor and three reviewers for commenting upon and improving this manuscript.

\section{Data Accessibility}

Isotopic data from winter and summer season were retrieved from a previous publication: Rigolet, C., Thiébaut, E., Dubois, S.F. (2014b) Food-web structures of subtidal benthic muddy habitats: evidence of microphytobenthos contribution supported by an engineer species. Marine Ecology Progress Series, 500, 25-41. (DOI: 10.3354/meps10685). The extensive list and isotopic composition of all species collected in winter and summer have been made publicly available online (DOI: $10.3354 /$ meps10685). Species isotopic data from spring and autumn used here are given in this manuscript and its supporting information. $\mathrm{R}$ scripts are made available by Sébastien Villéger 
(http://villeger.sebastien.free.fr/R\%20scripts/FDchange.r) and SIAR index by Andrew Jackson (cran.r-project.org/web/packages/siar/siar.pdf )

\section{References}

Badano, E.I. \& Cavieres, L.A. (2006) Ecosystem engineering across ecosystems: do engineer species sharing common features have generalized or idiosyncratic effects on species diversity? Journal of Biogeography, 33, 304-313.

Bearhop, S., Adams, C.E., Waldron, S., Fuller, R.A. \& MacLeod, H. (2004) Determining trophic niche width: a novel approach using stable isotope analysis. Journal of Animal Ecology, 73, 1007-1012.

Boecklen, W.J., Yarnes, C.T., Cook, B.A. \& James, A.C. (2011) On the use of stable isotopes in trophic ecology. Annual Review of Ecology, Evolution, and Systematics, 42, 411-440.

Brey, T. (1986) Formalin and formaldehyde-depot chemicals: Effects on dry weight and ash free dry weight of two marine bivalve species. Meeresforschung, 31, 52-57.

Brind'Amour, A. \& Dubois, S.F. (2013) Isotopic diversity indices: How sensitive to food web structure? PLOS ONE, 8, e84198.

Cardinale, B. J., Duffy, J. E., Gonzalez, A., Hooper, D. U., Perrings, C., Venail, P., Narwani, A., Mace, G. M., Tilman, D., Wardle, D. A., Kinzig, A. P., Daily, G. C., Loreau, M., Grace, J. B., Larigauderie, A., Srivastava, D. S. \& Naeem, S. (2012) Biodiversity loss and its impact on humanity. Nature, 486, 59-67.

Clark, C.M., Flynn, D.F.B., Butterfield, B.J. \& Reich, P.B. (2012) Testing the link between functional diversity and ecosystem functioning in a Minnesota grassland experiment. PLoS ONE, 7, e52821.

Clarke, K.R. (1990) Comparisons of dominance curves. Journal of Experimental Marine Biology and Ecology, 138, 143-157.

Cohen, J.E. \& Luczak, T. (1992) Trophic levels in community food webs. Evolutionary Ecology, 61, 73-89.

Dubois, S.F. \& Colombo, F. (2014) How picky can you be? Temporal variations in trophic niches of co-occurring suspension-feeding species. Food Webs, 1, 1-9.

Gamfeldt, L., Hillebrand, H. \& Jonsson, P.R. (2005) Species richness changes across two trophic levels simultaneously affect prey and consumer biomass. Ecology Letters, 8, 696-703.

Grime, J.P. (1998) Benefits of plant diversity to ecosystems: immediate, filter and founder effects. Journal of Ecology, 86, 902-910.

Hector, A., Schmid, B., Beierkuhnlein, C., Caldeira, M.C., Diemer, M., Dimitrakopoulos, P.G., Finn, J.A., Freitas, H., Giller, P.S., Good, J., Harris, R., Högberg, P., Huss, Danell, K., Joshi, J., Jumpponen, A., Körner, C., Leadley, P.W., Loreau, M., Minns, A., Mulder, C.P.H., O’Donovan, G., Otway, S.J., Pereira, J.S., Prinz, A., Read, D.J., Scherer-Lorenzen, M., Schulze, E.-D., Siamantziouras, A.-S.D., Spehn, E.M., Terry, A.C., Troumbis, A.Y., Woodward, F.I., Yachi, S. \& Lawton, J.H. (1999) Plant diversity and productivity experiments in European grasslands. Science, 286, 1123-1127.

Hoeinghaus, D.J. \& Zeug, S.C. (2008) Can stable isotope ratios provide for community-wide measures of trophic structure? Comment. Ecology, 89, 2358-2359.

Hooper, D.U., Chapin, F.S., Ewel, J.J., Hector, A., Inchausti, P., Lavorel, S., Lawton, J.H., Lodge, D.M., Loreau, M., Naeem, S., Schmid, B., Setälä, H., Symstad, A.J., Vandermeer, J. \& Wardle, D.A. (2005) Effects of biodiversity on ecosystem functioning: A consensus of current knowledge. Ecological Monographs, 75, 3-35.

Hulot, F.D., Lacroix, G., Lescher-Moutoue, F. \& Loreau, M. (2000) Functional diversity governs ecosystem response to nutrient enrichment. Nature, 405, 340-344. 
Jackson, A.L., Inger, R., Parnell, A.C. \& Bearhop, S. (2011) Comparing isotopic niche widths among and within communities: SIBER - Stable Isotope Bayesian Ellipses in R. Journal of Animal ecology, 80, 595-602.

Jones, C.G., Lawton, J.H. \& Shachak, M. (1997) Positive and negative effects of organisms as physical ecosystem engineers. Ecology, 78, 1946-1957.

Laliberté, E. \& Legendre, P. (2010) A distance-based framework for measuring functional diversity from multiple traits. Ecology, 91, 299-305.

Lavorel, S. \& Garnier, E. (2002) Predicting changes in community composition and ecosystem functioning from plant traits: revisiting the Holy Grail. Functional Ecology, 16, 545-556.

Layman, C.A., Arrington, D.A., Montana, C.G. \& Post, D.M. (2007) Can stable isotope ratios provide for community-wide measures of trophic structure? Ecology, 88, 42-48.

Layman, C.A., Araujo, M.S., Boucek, R., Hammerschlag-Peyer, C.M., Harrison, E., Jud, Z.R., Matich, P., Rosenblatt, A.E., Vaudo, J.J., Yeager, L.A., Post, D.M. \&Bearhop, S. (2012) Applying stable isotopes to examine food-web structure: an overview of analytical tools. Biological Review, 87, 545-562.

Mason, N.W.H., MacGillivray, K., Steel, J.B. \& Wilson, J.B. (2003) An index of functional diversity. Journal of Vegetation Science, 14, 571-578.

Mason, N.W.H., Mouillot, D., Lee, W.G. \& Wilson, J.B. (2005) Functional richness, functional evenness and functional divergence: the primary components of functional diversity. Oikos, 111, 112-118.

McDermott, J. (1993) Nemertea inhabiting the Haploops (Amphipoda) community of the northern Øresund with special reference to the biology of Nipponnemertes pulcher (Hoplonemertea). Hydrobiologia, 266, 15-28.

Mouchet, M.A., Villéger, S., Mason, N.W.H. \& Mouillot, D. (2010) Functional diversity measures: an overview of their redundancy and their ability to discriminate community assembly rules. Functional Ecology, 24, 867-876.

Mouillot, D., Graham, N.A.J., Villéger, S., Mason, N.W.H. \& Bellwood, D.R. (2013) A functional approach reveals community responses to disturbances. Trends in Ecology \& Evolution, 28, 167-177.

Mouillot, D., Villéger, S., Scherer-Lorenzen, M. \& Mason, N.W.H. (2011) Functional structure of biological communities predicts ecosystem multifunctionality. PLoSONE, 6, e17476.

Newsome, S.D., Martınez del Rio, C., Bearhop, S. \& Phillips, D.L. (2007) A niche for isotopic ecology. Frontiers in Ecology and the Environment, 5, 429-436.

Passarelli, C., Olivier, F., Paterson, D.M. \& Hubas, C. (2012) Impacts of biogenic structures on benthic assemblages: microbes, meiofauna, macrofauna and related ecosystem functions. Marine Ecology Progress Series, 465, 85-97.

Petchey, O.L. (2003) Integrating methods that investigate how complementarity influences ecosystem functioning. Oikos, 101, 323-330.

Petchey, O.L. \& Gaston, K.J. (2002) Functional diversity (FD), species richness and community composition. Ecology Letters, 5, 402-411.

Petchey, O. L, Hector, A. \& Gaston, K.J. (2004) How do different measures of functional diversity perform? Ecology, 85, 847-857.

R Development Core Team (2014) R: A language and environment for statistical computing. R Foundation for Statistical Computing, Vienna, Austria. URL http://www.Rproject.org/.

Raffaelli, D.G. (2006) Biodiversity and ecosystem functioning: issues of scale and trophic complexity. Marine Ecology Progress Series, 311, 285-294.

Reise, K. (2002) Sediment mediated species interactions in coastal waters. Journal of Sea Research, 48, 127-141. 
Ricciardi, A., Bourget, E. (1998) Weight-to-weight conversion factors for marine benthic macroinvertebrates. Marine Ecology Progress Series, 163, 245-251.

Ricotta, C. (2005) A note on functional diversity measures. Basic and Applied Ecology, 6, 479-486.

Rigolet, C., Dubois, S.F., Droual, G., Caisey, X. \& Thiébaut, E. (2012) Life history and secondary production of the amphipod Haploops nirae (Kaim-Malka, 1976) in the Bay of Concarneau (South Brittany). Estuarine, Coastal and Shelf Science, 113, 259-271.

Rigolet, C., Dubois, S.F. \& Thiébaut, E. (2014a) Benthic control freaks: Effects of the tubiculous amphipod Haploops nirae on the specific diversity and functional structure of benthic communities. Journal of Sea Research, 85, 413-427.

Rigolet, C., Thiébaut, E. \& Dubois, S.F. (2014b) Food web structures of subtidal benthic muddy habitats: evidence of microphytobenthos contribution supported by an engineer species. Marine Ecology Progress Series, 500, 25-41.

Schleuter, D., Daufresne, M., Massol, F. \& Argillier, C. (2010) A user's guide to functional diversity indices. Ecological Monographs, 80, 469-484.

Sulzman, E.W. (2007) Stable isotope chemistry and measurement: a primer. Stable isotopes in ecology and environmental science (eds. R. Michener \& K Lajtha), pp. 1-21. Blackwell Publishing, Malden

Tillin, H.M., Hiddink, J.G., Jennings, S. \& Kaiser, M.J. (2006) Chronic bottom trawling alters the functional composition of benthic invertebrate communities on a sea-basin scale. Marine Ecology Progress Series, 318, 31-45.

Tilman, D., Knops, J., Wedin, D., Reich, P., Ritchie, M. \& Siemann, E. (1997) The influence of functional diversity and composition on ecosystem processes. Science, 277, 1300- 1302.

Villéger, S., Mason, N.W.H. \& Mouillot, D. (2008) New multidimensional functional diversity indices for a multifaceted framework in functional ecology. Ecology, 89, 2290-2301.

\section{Figure captions}

Fig. 1. Overlaps of the total extents of the two communities (Amphiura and Haploops) in winter, spring, summer and autumn for the whole communities (a-d) or for only species representing $75 \%$ of the biomass (e-h). Isotopic compositions and convex hull areas of species are plotted in light grey and black in Amphiura and Haploops communities, respectively. Each point of the graphic represents the mean value of 3 individuals (or 3 pools of individuals), but error bars were removed for clarity. Plots $2 \mathrm{i}$ to $2 \mathrm{p}$ correspond to the seasonal variations of the two studied communities, with all species weighted by their biomasses. $\mathrm{N}$ corresponds to the number of species analysed for isotopic composition. For clarity purposes, only the names of species with relative biomass over $5 \%$ are represented. For each plot, the $\mathrm{x}$ axis corresponds to $\delta^{13} \mathrm{C}$ and the y-axis to $\delta^{15} \mathrm{~N}$.

Fig. 2. Bar-plots comparing IFI obtained from the Haploops community vs. the Amphiura community in winter (a), spring (b), summer (c) and autumn (d) and for the 3 facets of the isotopic functional diversity (i.e. IFR, IFD and IFE). Each bar indicates the difference in each IFI value between Haploops and Amphiura communities ( $\Delta=$ Haploops value - Amphiura value). Left panels showed isotopic functional indices calculated on the overall food web (on all species). Right panels showed IFI differences computed on $75 \%$ of the benthic biomass. IFI unweighted by species biomasses (i.e. IFRic, SEAc, CD and NND) are marked *.

Fig. 3.Two-dimensional plot generated by the Principal Component Analysis (left) and overall pattern of correlations (right) between the 11 calculated Isotopic Functional Indices 
(variables) presented according to the 1-2 axes map. ' $\mathrm{A}$ ' and ' $\mathrm{H}$ ' correspond to Amphiura and Haploops communities, respectively. 

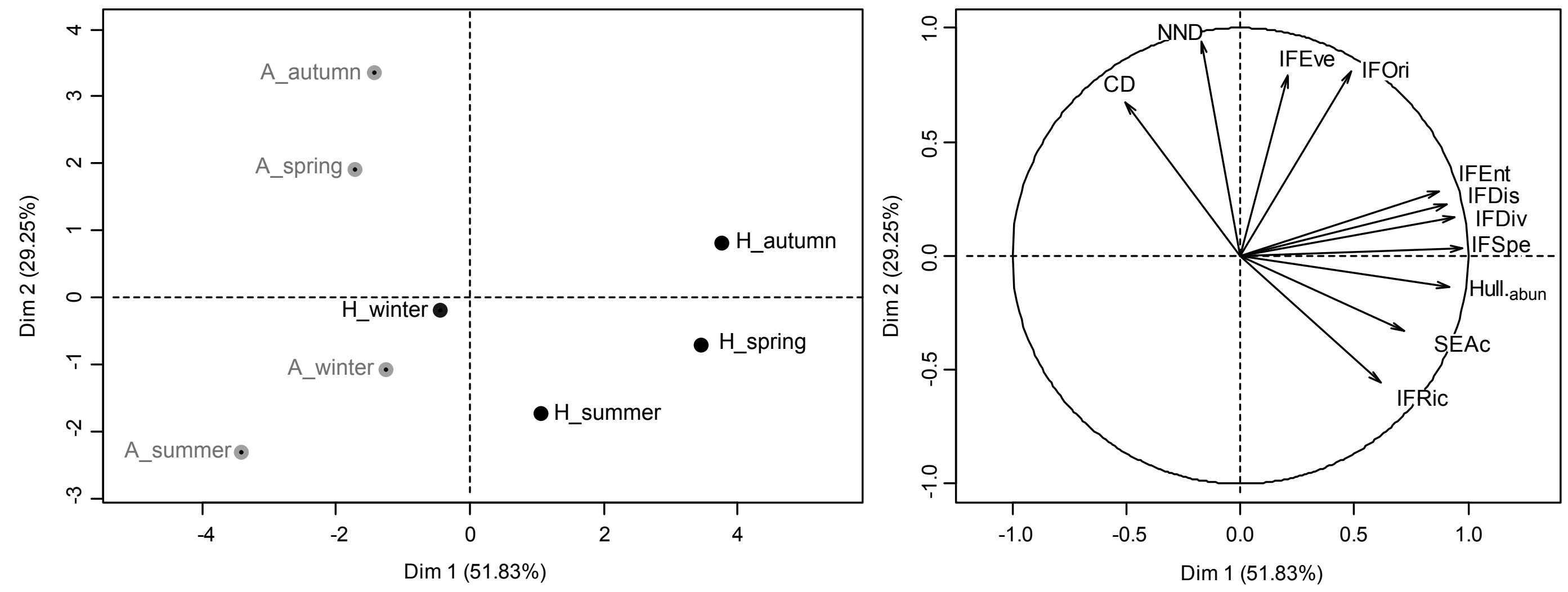

Figure 3 